\title{
The Landscapes of West Africa—40 Years of Change
}

What has driven changes in land use and land cover in West Africa during the past 40 years? What trends or patterns can be discerned in those changes? To answer these questions, the U.S. Geological Survey (USGS) West Africa Land Use Dynamics project partnered with the Comité permanent Inter-états de Lutte contre la Sécheresse dans le Sahel (CILSS) and the U.S. Agency for International Development/West Africa (USAID/West Africa) to map land use and land cover across the region for the years 1975, 2000, and 2013 (Cotillon, 2017). This cooperative effort has resulted in the publication of a 219-page atlas, "Landscapes of West Africa: A Window on a Changing World" (CILSS, 2016). The atlas uses satellite imagery, maps, and pictures to tell a complex story of landscape change, at regional and national scales. It includes a collection of focused studies, some of which raise cause for concern and others that provide considerable hope.

\section{What is the Story of "Landscapes of West Africa"?}

The atlas, "Landscapes of West Africa: A Window on a Changing World," highlights land use and land cover change in the 17 countries of West Africa, from Mauritania to Chad, and from the Sahel to the Gulf of Guinea-including the Cabo Verde archipelago (CILSS, 2016). Using three key time periods (years) - 1975, 2000, and 2013 - the atlas describes major land cover transformations over the past 40 years in each country and across the region as a whole. The drivers of change, as well as their environmental and socioeconomic effects, are also discussed. The story is told through maps with statistics that detail the rate, magnitude, and location of land cover change. Beyond words, the atlas makes ample use of photographs and satellite imagery to make land cover change more understandable to the people living in West Africa and around the globe.

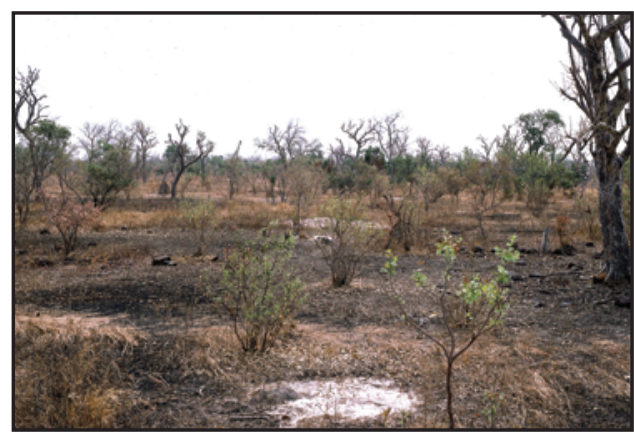

At the center of all these stories are the roughly 335 million people who coexist in this environment, which is roughly three times the number of people that lived in the same space nearly four decades ago. This rapid growth of West Africa's population has driven dramatic loss of savanna, woodlands, forests, and steppe. Most of this transformation has been to agriculture - the cultivated area doubled between 1975 and 2013. Much of that agriculture feeds a growing rural population, but an increasing fraction goes to large cities like Lagos (Nigeria), Ouagadougou (Burkina Faso), Dakar (Senegal), and Accra (Ghana) as the proportion of West Africans living in urban areas has risen from 8.3 percent in 1950 to nearly 44 percent in 2015 . The people of West Africa and their leaders must navigate an increasingly complex path to meet the immediate needs of a growing population while protecting the environment that will sustain it into the future. Aimed at both decision makers and the general

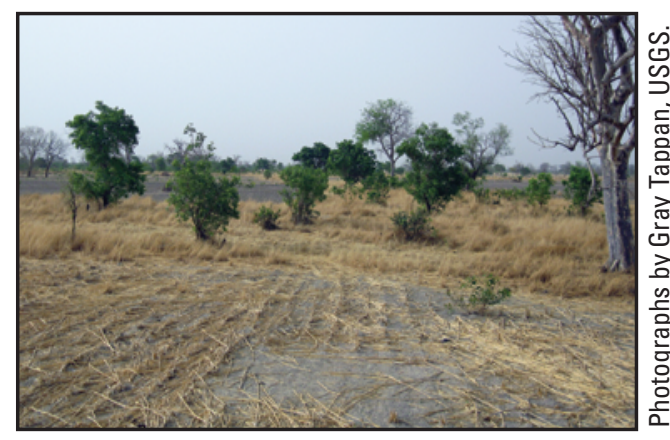

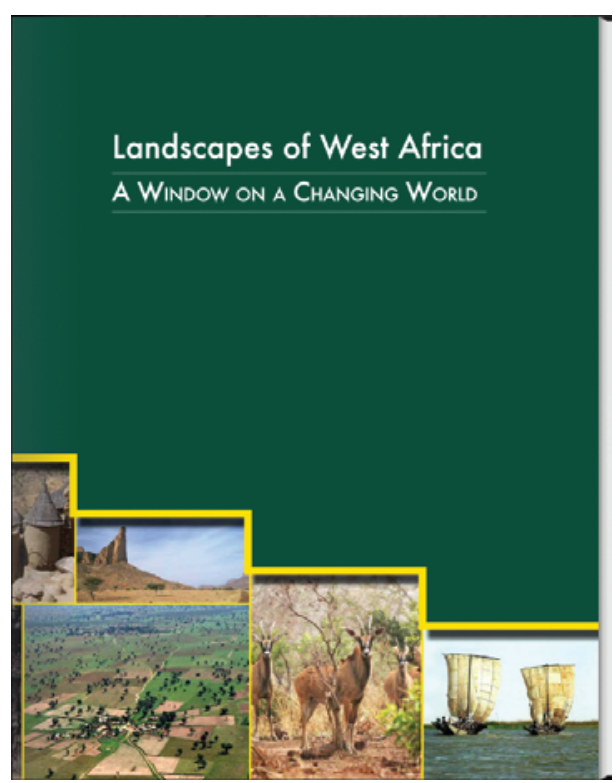

“Landscapes of West Africa: A Window on a Changing World" atlas front cover.

public, the West Africa atlas has a goal of raising awareness about the environmental changes - many worrisome, others hopeful- that are taking place across the landscape.

Conversion of wooded savanna to agriculture (millet and peanut, postharvest) in central Senegal, south of Kaffrine, between 1994 and 2010. 
